Ellen S. Rome, MD, MPH

Head, Center for Adolescent Medicine,

Center for Pediatric Endocrinology,

Cleveland Clinic; Professor, Cleveland Clinic

Lerner College of Medicine of Case Western

Reserve University, Cleveland, $\mathrm{OH}$
Perry B. Dinardo, MA

Cleveland Clinic Lerner College of Medicine

of Case Western Reserve University,

Cleveland, $\mathrm{OH}$
Veronica E. Issac, MD

Center for Adolescent Medicine

Department of Pediatric Endocrinology,

Cleveland Clinic

\title{
Promoting resiliency in adolescents during a pandemic: A guide for clinicians and parents
}

\section{ABSTRACT}

The COVID-19 pandemic has dramatically affected every aspect of daily life. Parents of adolescents, in particular, may be facing unique challenges in helping them navigate unexpected changes to their daily routine. This article discusses how adolescents may respond to stressful and traumatic situations and provides recommendations for clinicians who may be advising parents of adolescents or parenting their own children.

\section{KEY POINTS}

Young adults who are socially isolated during COVID-19 may experience intense feelings of loneliness, increasing their risk for depression and anxiety.

Primary care providers can help their adolescent patients by ensuring they continue to receive immunizations on time and have access to prescribed medications, as well as scheduling future well visits and contraceptive counseling when needed.

Family support is key to helping adolescents cope with the negative effects of stress caused by the pandemic.

When advising parents of teens, discuss ways in which they can support their child. This can include acknowledging their disappointment about missing important social events, encouraging time limits for social media, and helping them practice "adulting" skills such as planning and cooking meals.
THE COVID-I9 PANDEMIC has introduced great global uncertainty, affecting every aspect of daily life and requiring sudden adaptation to ever-changing circumstances. Parents with children of all ages have seen enormous and unexpected changes in how their children are engaged in and out of the home. In particular, parents of adolescents may face unique challenges in helping their children navigate changes to their daily routine.

This article draws on experience from prior global catastrophes and suggests evidencebased counseling strategies for clinicians who are advising parents of adolescents and their families during the pandemic. These strategies can also be used by clinicians who are themselves parents of adolescents.

\section{SOCIAL DISTANCING:}

\section{A SOURCE OF STRESS FOR ADOLESCENTS}

Adolescence is a developmental stage characterized by changes to parental and peer relationships, including a decrease in the amount of time spent with family and an increase in the amount of time spent with peers. ${ }^{1}$ Many, but not all, experience a range of intense and volatile emotions. ${ }^{2}$ A decrease in the quantity and quality of peer interactions for any reason can lead to intense feelings of loneliness, ${ }^{3}$ which has been identified as a risk factor for mental health disorders such as depression and anxiety. ${ }^{4}$ Loneliness has also been linked to impaired sleep quality, ${ }^{5}$ eating disorders, ${ }^{6}$ and increased risk of alcohol and drug abuse, ${ }^{7}$ among other mental health concerns. 
While these correlations have been observed across the life span, ${ }^{8}$ adolescents are more likely to feel lonely due to the high value attached to peer friendships and romantic relationships during this developmental period. ${ }^{3}$ Young adults who are socially isolated during COVID-19 may experience greater feelings of loneliness and may be at increased risk of depression. ${ }^{3}$

\section{EFFECTS OF STRESS ON CHILDREN AND ADOLESCENTS: THE ACE STUDY}

Although no study has looked at the effects of a pandemic on adolescent health, the effects of various types of acute and chronic stress have been widely studied in children and adolescents. The Adverse Childhood Experience (ACE) study, conducted in the 1990s in San Diego, was one of the first to link stressful experiences in childhood with later mental and physical health outcomes. ${ }^{9}$

While the original ACE study focused on events of abuse or neglect, the adverse experiences included in later iterations of the study included a wide array of more insidious stressors such as parental stress, financial
A decrease in peer interactions can lead to intense feelings of loneliness hardship in the household, and discrimination-many of which are present with the COVID-19 pandemic. These stressors resulted in depression and a higher prevalence of risky behaviors in pregnant women who experienced adverse childhood experiences and a higher risk of ischemic heart disease in adult survivors. ${ }^{9-13}$

Data from the ACE study also suggest that there is a dose-response relationship between the number of adverse childhood experiences and risk of negative health outcomes later in life. These include many leading causes of death in the United States such as cancer, stroke, diabetes, and suicide. ${ }^{13,14}$ Certain individuals may be more predisposed to long-lasting adverse effects of stressful events, based on a complex interplay of genetic predisposition and environmental factors. ${ }^{14}$

Fortunately, if exposure to stressors resolves after a short time, and if the individual can learn effective coping mechanisms, research suggests that long-term effects can be mitigated. ${ }^{15}$

\section{HOW CLINICIANS CAN HELP FAMILIES GET THROUGH THE PANDEMIC}

Helping adolescent patients and their families attend to the basics remains important. The American Academy of Pediatrics notes that missed immunizations during a pandemic may lead to outbreaks of preventable illnesses. ${ }^{16}$ Missed well visits or contraceptive counseling visits may result in increased teen pregnancies in the next year.

Additionally, children and adolescents with chronic disease may be more or less compliant with medication schedules when at home with parents, and access to medication may be interrupted because there are fewer routine trips to the pharmacy. Stress can cause chronic illness to flare, as well.

Astute clinicians can partner with their adolescent patients and the patients' parents on ways to support responsible self-care. For instance, ask the patient to consider using a smartphone app that automatically reminds users when it is time to take their medications. Patients can then teach their parents how to do the same.

Experience with other global tragedies reveals that disaster training courses can be useful for healthcare providers, including pediatricians, internists, and family physicians involved in the care of youth impacted by war or other tragedies. ${ }^{17}$ These courses can help providers understand the context-specific health needs of children, the management of chronic conditions, and the care of children with special healthcare needs in conflict and postconflict settings, including the current one.

We recommend the following resources:

- American Academy of Pediatrics. www. aap.org/en-us/advocacy-and-policy/aaphealth-initiatives/Children-and-Disasters/Pages/default.aspx

- Administration for Children and Families. www.acf.hhs.gov/trauma-toolkit/emergency-crisis-and-disaster

- Centers for Disease Control and Prevention. www.cdc.gov/childrenindisasters/children-disaster-help.html.

\section{FAMILY SUPPORT IS KEY}

Research suggests that the negative effects of stress may be buffered by supportive rela- 
tionships with adults, such as parents or other caregivers. ${ }^{15}$ Refugee children in high-income countries showed improved mental health and well-being when they experienced high parental support and family cohesion, selfreported encouragement from friends, and positive experiences at school. ${ }^{17,18}$ Youth in an indigent area of Rotterdam showed more resiliency when community ties were deepened through experiential learning, and were better equipped to address uncomfortable issues. ${ }^{19} \mathrm{Abma}$ et $\mathrm{a}^{19}$ refer to these measures as "sowing seeds to harvest healthy adults."

With this in mind, parents can take several actions to support their teens during the $\mathrm{CO}$ VID-19 pandemic.

\section{Explain anxiety: The fight-or-flight response} Anxiety can be "normalized" and explained. It is the way the body alerts itself to danger, which is an appropriate initial response to COVID-19.

When explaining this series of complex metabolic events to a young person, keep it simple: anxiety activates your fight-or-flight response, which gives you a surge of adrenaline. This adrenaline allows you to detect the threat and outrun it, and is a useful mechanism. But if this response is constantly activated by potential threats, the body may not be able to tell the difference between a serious threat and a less serious threat, leading to severe anxiety about COVID-19.

Parents can help anxious adolescents channel their anxiety in more productive ways, such as doing craft projects (eg, learning to sew fabric masks for family members). The body is not made to live on constant adrenaline, so coping mechanisms such as yoga, meditation, taking a walk in nature, and listening to music when isolated at home can help. Writing, drawing, and anything creative can also activate other parts of the brain and calm the adrenaline surge. Parents can also encourage other distracting activities, such as going for a walk or jog outside (while continuing to stay away from others).

At the same time, it is also important to give teens privacy and space to be alone when needed, ${ }^{20}$ such as in their bedroom or in another quiet space.

\section{Addressing news and social media}

A constant stream of news and social media can contribute to a sense of fear and helplessness for adolescents and their parents. As news articles continue to discuss the COVID-19 infection rate and the need to "flatten the curve," anxiety, depression, and emotional distress increase, a phenomenon referred to as the "second curve." 21

We encourage parents to talk to adolescents about setting limits on the amount of time they spend reading about current events. ${ }^{22}$ Parents may also choose to model this behavior by taking a break from social media at certain times of the day or week. ${ }^{23}$

Enforcing limits on time spent using technology may be more challenging than parents are used to, because the same devices used for reading the news, such as smartphones and laptops, are also being used now to attend virtual classes and stay connected with friends and family members. Parents may choose to modify previous limits set on technology use. However, it may be useful to continue to set some adjusted limits and expectations about times when technology should not be used, such as during dinner or after bedtime.

Parents should make time for adolescents to talk about news articles or social media posts they have seen, as current news articles can be upsetting for readers. ${ }^{23}$

Parents can discuss how some information on the Internet and social media may be incorrect or misleading. However, current information from reputable news sources can be equally upsetting, given the uncertainty of the current global situation. A particularly anxious or depressed child or adolescent may require curbing of media time and less discussion to avoid a constant state of anxiety or stress.

The parent or provider can also offer useful perspectives, helping to keep adolescents from overestimating the risks of COVID-19 or underestimating their own ability to keep themselves safe. ${ }^{22}$

\section{Watch for downstream effects of stress}

Some adolescents may experience an increase in somatic complaints such as chronic headaches and abdominal pain, with or without awareness of the role of stress in amplifying
Activities such as yoga, meditation, a nature walk, and listening to music can help one cope 
this pain. Disrupted sleep cycles (excessive sleep or too little sleep) can also make the young person feel worse, be more irritable, or less resilient. Maladaptive coping strategies can emerge, including disordered eating, self-harm, and substance use. The adolescent's lack of abstract thought may impede the ability to see consequences in the moment.

\section{Acknowledge uncertainty and disappointment}

The inability to participate in team sports, attend in-person social events, and spend time with friends face-to-face may leave teenagers feeling bored, lonely, and sad. Loss of social milestones, including graduation and prom, can exacerbate these feelings in adolescents and parents. ${ }^{20}$ While some of these events may be postponed and rescheduled for a later date, the adolescent may still feel a sense of grief or loss. ${ }^{20}$

Parents should anticipate and validate these feelings in their adolescent children. Many young people acknowledge the conflict between perceived selfish desires and the good of the larger community; allowing teens to share and reconcile their own needs with what
Families can discuss how each member is responsible for staying at home to protect themselves and the community they know is right can help them process this juxtaposition of feelings. Adolescents are perceptive and aware of the stress experienced by adults in the household and in society ${ }^{22}$; adult stress regarding canceled plans can therefore increase adolescents' stress level.

An "ask-tell-ask" approach can be particularly useful in engaging the young person, expressing empathy, and helping the adolescent get to the "right" solution a little more gracefully.

To use this model, parents can ask the adolescent how they think personal and family sacrifices, such as canceling a vacation or not visiting friends, can protect the community and contribute to decreasing the strain on local hospitals and healthcare workers. ${ }^{22}$ After listening closely to their response, parents can fill in any information gaps in the adolescent's understanding while continuing to ask the adolescent what they think.

\section{A partner in problem-solving, not a problem to be solved}

If the parent requires help watching a younger sibling, the parent can ask, "I am going to need to get XYZ done, and I know you have homework to do. I am going to need some help to get this done. What works best for you? Or how should we best divide and conquer?"

Hold high expectations for adolescents, with flexibility. Ask what schedule works best for them to get work done, and also to get adequate sleep and time for online socialization, exercise, or other downtime. Brainstorm solutions that work for children and adolescents without disrupting the household.

\section{Help adolescents assume responsibility for following guidelines}

As time goes by and adolescents experience a growing sense of confinement at home, they may begin to question the guidelines for social distancing and may want to push the limits of what is allowed.

Parents can discuss with adolescents the most current US Centers for Disease Control and Prevention guidelines for social distancing and why they are important. Since the general public is now widely aware that older and immunocompromised individuals are at higher risk for complications from COVID-19, adolescents, particularly those who do not have immunodeficiencies, may not understand the importance of strictly adhering to the guidelines themselves since they are less likely to suffer negative effects of infection.

Abstract thought, or the ability to foresee consequences, is a cognitive development that happens in late adolescence, usually age 18 and older. Keeping examples more concrete can help ground the discussion in ways that connect the adolescent to the situation, as in the impact on a beloved elderly family member, or of a family member who has cancer or is otherwise immunocompromised.

Families can discuss how each member is responsible for staying home in order to protect themselves as well as the community. Adolescents may feel that meeting up with friends is not particularly risky for them personally, but doing so could put other people in the household at risk, including:

- Those who are immunocompromised, or otherwise at a higher risk for COVID-19

- A caregiver for a vulnerable individual

- An essential worker who comes into contact with other people outside the household. 
Parents can model this behavior by strictly adhering to the guidelines themselves. If adolescents see their parents disregarding guidelines for social distancing, they may ask to do so themselves. "Do as I say, not as I do" has not worked well for children, adolescents, or adults.

\section{Help adolescents develop life skills}

While at home, parents can take opportunities to teach their adolescents life skills such as planning and cooking meals. ${ }^{24}$ Adolescents can also help with chores such as laundry and dishes and practice "adulting." Experiential learning could include learning to manage a checking account and plan a weekly budget.

\section{Laughter is some of the best medicine}

Never underestimate the power of a good belly laugh to relieve tension. If laughter does not come naturally to a young person or a family, challenge the teen to find something on YouTube or Instagram that they find amusing and to share it with you. The same can be done by watching a fun movie together as a family. As Dr. Colleen Hacker ${ }^{25}$ states, "Laughter is the antidote to stress." But remember always to laugh with, never at, the adolescent.

\section{Instill a sense of gratitude}

As part of the daily routine of family dinner, ask each family member to share something that they are grateful for. Gratitude highlights connection and is strongly linked to emotional well-being and life satisfaction. ${ }^{26}$ The act of focusing on gratitude helps youth pay attention to what is positive in their life, instead of becoming overwhelmed by negatives.

\section{REFERENCES}

1. Larson R. The uses of loneliness in adolescence. In: Rotenberg K, Hymel S, eds. Loneliness in childhood and adolescence. Cambridge, England: Cambridge University Press; 1999:244-262.

2. Guyer AE, Silk JS, Nelson EE. The neurobiology of the emotional adolescent: from the inside out. Neurosci Biobehav Rev 2016; 70:74-85. doi:10.1016/j.neubiorev.2016.07.037

3. Matthews T, Danese A, Wertz J, et al. Social isolation, loneliness and depression in young adulthood: a behavioural genetic analysis. Soc Psychiatry Psychiatr Epidemiol 2016; 51(3):339-348. doi:10.1007/s00127-016-1178-7

4. Heinrich LM, Gullone E. The clinical significance of loneliness: a literature review. Clin Psychol Rev 2006; 26(6):695-718. doi:10.1016/j.cpr.2006.04.002

5. Matthews T, Danese A, Gregory AM, Caspi A, Moffitt TE, Arseneault L. Sleeping with one eye open: loneliness and sleep quality in young adults. Psychol Med 2017; 47(12):2177-2186. doi:10.1017/50033291717000629
Find joy and wonder in each day, and share that lens with one another

Finding small ways to be joyful can help the young and old survive rough times. Toddlers do this naturally; adolescents may need more guidance to start the process. Take a virtual tour of a museum or natural setting and then apply the same focus to walking through one's house or backyard.

Virtual input from grandparents and remote loved ones can also create personal connection to items or photos discovered on the "tour." This kind of connection benefits individuals across generations and can be a point for thoughtful reflection, shared laughter, and other emotions.

Keep in mind that each day does not have to be a whirlwind of activity from dawn to dusk. The forced slowdown of social isolation can be a time for families to pause, reflect, prioritize, and enjoy the simple things.

\section{YOUNG PEOPLE THRIVE}

Young people thrive with clear, caring, and open communication. Children take their cues from parents' anxiety levels and reactions to COVID-19. Although school-age children may lack the emotional maturity to tolerate uncertainty, adults and caregivers can ask about their fears, respond with openness and empathy, and problem-solve together. Adolescents - digital natives born and raised in an era of technology - may devise their own solutions to political, ethical, financial, and practical challenges posed by this pandemic. Approach them as a resource with whom to collaborate on innovative solutions in this new reality.
This can be a time for families to pause, reflect, prioritize, and enjoy the simple things

6. Coric D, Murstein B. Bulimia nervosa: prevalence and psychological correlates in a college community. Eating Disorders 2007; 1(1):39-51, doi:10.1080/10640269308248265

7. Sadava SW, Pak AW. Problem drinking and close relationships during the third decade of life. Psychol Addict Behav 1994; 8(4)251-258. doi:10.1037/0893-164X.8.4.251

8. Cacioppo JT, Hawkley LC, Thisted RA. Perceived social isolation makes me sad: 5-year cross-lagged analyses of loneliness and depressive symptomatology in the Chicago Health, Aging, and Social Relations Study. Psychol Aging 2010; 25(2):453-463. doi:10.1037/a0017216

9. Felitti VJ, Anda RF, Nordenberg D, et al. Relationship of childhood abuse and household dysfunction to many of the leading causes of death in adults. The Adverse Childhood Experiences (ACE) Study. Am J Prev Med 1998; 14(4):245-258. doi:10.1016/s0749-3797(98)00017-8

10. Chung EK, Mathew L, Elo IT, Coyne JC, Culhane JF. Depressive symptoms in disadvantaged women receiving prenatal care: the influence of adverse and positive childhood experiences. Ambul 
Pediatr 2008; 8(2):109-116. doi:10.1016/j.ambp.2007.12.003

11. Wade R Jr, Shea JA, Rubin D, Wood J. Adverse childhood experiences of low-income urban youth. Pediatrics 2014; 134(1):e13-e20. doi:10.1542/peds.2013-2475

12. Chung EK, Nurmohamed L, Mathew L, Elo IT, Coyne JC, Culhane JF. Risky health behaviors among mothers-to-be: the impact of adverse childhood experiences. Acad Pediatr 2010; 10(4):245-251. doi:10.1016/j.acap.2010.04.003

13. Dong M, Giles WH, Felitti VJ, et al. Insights into causal pathways for ischemic heart disease: Adverse Childhood Experiences study. Circulation 2004; 110(13):1761-1766. doi:10.1161/01.CIR.0000143074.54995.7F

14. Bucci M, Marques SS, Oh D, Harris NB. Toxic stress in children and adolescents. Adv Pediatr 2016; 63(1):403-428. doi:10.1016/j.yapd.2016.04.002

15. Garner AS, Shonkoff JP; Committee on Psychosocial Aspects of Child and Family Health; Committee on Early Childhood, Adoption, and Dependent Care; Section on Developmental and Behavioral Pediatrics. Early childhood adversity, toxic stress, and the role of the pediatrician: translating developmental science into lifelong health. Pediatrics 2012; 129(1):e224-e231. doi:10.1542/peds.2011-2662

16. American Academy of Pediatrics. Guidance on providing pediatric well-care during COVID-19. Accessed July 21, 2020. https://services. aap.org/en/pages/2019-novel-coronavirus-covid-19-infections/guidance-on-providing-pediatric-well-care-during-covid-19/

17. Kadir A, Shenoda S, Goldhagen J, Pitterman S; Section on International Child Health. The effects of armed conflict on children. Pediatrics 2018; 142(6):e20182586. doi:10.1542/peds.2018-2586

18. Fazel M, Reed RV, Panter-Brick C, Stein A. Mental health of displaced and refugee children resettled in high-income countries: risk and protective factors. Lancet 2012; 379(9812):266-282.
doi:10.1016/S0140-6736(11)60051-2

19. Abma T, Lips S, Schrijver J. Sowing seeds to harvest healthier adults: the working principles and impact of participatory health research with children in a primary school context. Int J Environ Res Public Health 2020; 17(2):451. Accessed July 21, 2020. doi:10.3390/ijerph17020451

20. Damour L. Quaranteenagers: strategies for parenting in close quarters. New York Times March 19, 2020. https://www.nytimes. com/2020/03/19/well/family/coronavirus-covid-teenagers-teensparents-kids-family-advice.htm

21. Your Teen for Parents. Our emotional well-being. https://yourteenmag.com/digital/special-issue/. Accessed July 21, 2020.

22. Damour L. 5 Ways to help teens manage anxiety about the coronavirus. New York Times March 11, 2020. https://www.nytimes. com/2020/03/11/well/family/coronavirus-teenagers-anxiety.html

23. American Academy of Pediatrics. AAP: finding ways to keep children occupied during these challenging times. https://www.aap. org/en-us/about-the-aap/aap-press-room/Pages/AAP-Finding-Waysto-Keep-Children-Occupied-During-These-Challenging-Times-.aspx . Accessed July 21, 2020.

24. Skolnik D; Your Teen for Parents. My teenager's school is closed indefinitely. Now what? https://yourteenmag.com/digital/specialissue/. Accessed July 21, 2020

25. Hacker D. Laughter permitted with Julie Foudy. Accessed July 21, 2020. https://podcasts.apple.com/us/podcast/episode-31-dr-colleenhacker/id1455251280?i=1000468792571

26. Emmons RA, Stern R. Gratitude as a psychotherapeutic intervention. J Clin Psychol 2013; 69(8):846-855. doi:10.1002/jclp.22020

Address: Ellen S. Rome, MD, MPH, Center for Pediatric Endocrinology, R3,

Cleveland Clinic, 9500 Euclid Avenue, Cleveland, OH 44195; romee@ccf.org 